\title{
Linguistic Analysis of Human Heart Rate and 15 Types of its Poincaré Plots
}

\author{
Cherkay A.D. ${ }^{1}$, Vlasov Yu.A. ${ }^{2}$ \\ ${ }^{1}$ Moscow Aviation Institute (National Research University) \\ ${ }^{2}$ Novosibirsk National Research State University \\ cherkay_ad@mail.ru, vlasov.yuri.a@yandex.ru
}

\begin{abstract}
This article presents a method of extracting repeating sequences belonging to an $\varepsilon$-tube for a given $\varepsilon$ from the impulse signals generated by heart of man. The method was developed by the authors in 1970s and enables us to identify repeating pieces, words (or patterns or matrices), in the rows of RRintervals of electrocardiograms. There are 15 types of Poincare plot of the heart rhythm, constructed at the same time, using 342 sequences of RR intervals of 309 patients. Using night data (at rest) of the 24 hour records of RR-intervals 216 patients are installed repeatability of these15 types of Poincaré plot. The authors also identified 15 types of Poincare plot for the heart rate, the analysis of which allowed authors to see geometric figures that look like letters and other symbols used in written language, as well as parts of circles or ellipses. For one of these 15 types of Poincaré plot rhythm of the heart, which was found in 29 patients, a high one was detected up to hundred times, the frequency of triads and quadruples of RR-intervals.
\end{abstract}

Keywords: heart rate variability, RR-interval, linguistic analysis, patterns, Poincaré plot.

\section{Лингвистический анализ ритма сердца и 15 типов его диаграмм Пуанкаре}

\author{
Черкай А.Д. ${ }^{1}$, Власов Ю.А. ${ }^{2}$ \\ ${ }^{1}$ Московский авиационный институт (научный исследовательский университет) \\ ${ }^{2}$ Новосибирский наииональный исследовательский государственный университет
}

В статье рассматривается разработанный в 70-х годах XX столетия авторами работы метод выделения в генерируемых организмом импульсных сигналах повторяемых последовательностей, принадлежащих $\varepsilon$-трубке с заданным $\varepsilon$, обеспечивающий выявление в рядах RR-интервалов электрокардиограмм повторяемых фрагментов - “слов" (шаблонов, паттернов, матриц), и результаты проверки повторяемости, выделенных авторами тогда же 15 типов Poincaré plot (диаграмм Пуанкаре) ритма сердца. Эта проверка, проведенная с использованием данных ночной части (в покое) суточных последовательностей RR-интервалов 216 пациентов, подтвердила повторяемость большинства из 15 этих типов. Анализируя изображения их на Poincaré plot, авторы обнаружили геометрические формы, которые в некоторых случаях выглядели как буквы и другие символы, используемые при рукописном их написании, наряду с частями кругов или эллипсов. Для одного из этих 15 типов Poincaré plot, встретившегося у 29 пациентов выявлена высокая, до ста раз, повторяемость триад и четверок RR-интервалов.

Ключевые слова: ритм сердиа, RR-интервалы, лингвистический анализ, паттерны, Poincaré plot.

\section{Introduction}

The heart rate of cardiac contractions is one of the natural output signals formed with the involvement of the brain. We can watch it easily and such observation can help to understand the general logic of the temporal design of biological signals. The actual biological signals contain elements of both determinacy and random. One of the tasks of processing them is identifying and analyzing the determinate elements of such signals. Techniques of data processing being used vary. As the genetic code was discovered, it became immediately clear that the language was one of the fundamentals for the germ of life and every animate being's functioning. The language is also the origin of the signals generated by those living beings. That is why the linguistic method for heart rate analysis seems to be to be one of the most relevant. This idea underlay the authors' paper [1] which presented the linguistic analysis method developed by the authors and showed how the method makes it possible to extract reoccurring fragments from the sequentially measured RR-intervals on a human ECG that form words (or patterns or matrices) that, in turn, form a dictionary. 
The way the specific implementations which constitute the whole language are built up from the words is governed by the formation rules of the language - its grammar. The reason why the authors proceeded to the development and application of linguistic methods for analyzing of the heart rate had been identifying [2], [3] repeatability of consequential pairs and triads of the ECG RR-intervals, as well as curves on planes, which are now called diagrams Poincare plotformerly known and called scattergrams [4], [5]. Along with statistical and other mathematical methods [6-10], Poincaré diagrams are widely used [11-15] in analyzing of heart rate.

\section{Papers Related to Linguistic Analysis of Heart Rate}

As we were writing our paper [1], some other authors discussed [16-18] the issues of using linguistic approach to the problems of analyzing, interpreting, and recognizing curves and 3D images. However, recognizing words, or patterns, in RR-interval sequences had turned to be quite a difficult task for the researchers. It was as late as the beginning of the 21st century [19], [20] and others. They extracted templates from the rows of zeros ( 0 ) and ones (1) obtained by converting the RRinterval sequences in them. Usefulness of such symbolic character encoding of changes in pairs of RR intervals, peaks $\mathrm{R}$ and angles in cardio cycles demonstrates Uspensky's proposal method of diagnosis of internal organs by ECG [21], [22]. And only after the publication in 2004 of J. Hawkins \& S. Blakeslee's book "On Intellect" [23] around the world began a truly active selection of patterns and templates in various data, using neural networks and in the analysis of processes [24]. Let us remark that for the purpose of researching into nonlinear characteristics of the variability of processes, including the heart rate, within the framework of the chaos theory using $\varepsilon$-tubes, the recurrence plots are visualized on a surface [25], [26].

\section{Linguistic Analysis of the Heart Rate}

The procedure of linguistic analysis of the ECG RRintervals proposed by the authors is based on identifying repeating sequences of RR-intervals belonging to an $\varepsilon$ tube for a given $\varepsilon$. Here it is in concise form:

Let $X^{(1, N)}=\left\{X_{1}, \ldots, X_{N}\right\}$ be the sequence of $N$ measurements of ECG RR-intervals. Then $X^{(i, m)}=\left\{X_{i}\right.$, $\left.X_{i+1}, \ldots, X_{i+m-1}\right\}$ is a chain of $m$ elements of the sequence in question placed according to their sequence order in $X^{(1, N)}$ starting with the $i$-th element $(1 \leq i \leq N-m+1, \quad 2<m \leq N)$. Assign the numbers $k=1,2, \ldots$ to various chains $X^{\left(i_{k}, m_{k}\right)}$ according to the sequence order of their first element $X_{i_{k}}$ in $X^{(1, N)}$. Thus, for all $k=1,2, \ldots$ we have $i_{k}<i_{k+1}$.

The subsequences $X^{\left(i_{k}, m_{k}\right)}(k=1,2, \ldots)$, for which there exist such $j_{k}\left(i_{k} \leq j_{k} \leq i_{k}+m_{k}-1, \quad k=1,2, \ldots\right)$ that the following inequality holds for any $q=\underline{m}, \bar{m}$, where $\underline{m}=\min _{k}\left(i_{k}-j_{k}\right), \bar{m}=\max _{k}\left(m_{k}+i_{k}-j_{k}-1\right)$

$$
\max _{k}\left(X_{j_{k}+q}\right)-\min _{k}\left(X_{j_{k}+q}\right) \leq \varepsilon,
$$

are thosevery chains belonging to the $\varepsilon$-tube.

To obtain a separate pattern in the shape of a matrix chain considering

$$
\varepsilon=K_{\varepsilon} \bar{X}\left(\bar{X}=\frac{1}{N} \sum_{i=1}^{N} X_{i}, K_{\varepsilon}=0.02 \div 0.05\right),
$$

one should select such triads $X^{\left(i_{k}, 2\right)}(k=1,2, \ldots)$ from $X^{(1, N)}$ that they belong to the same $\varepsilon$-tube while the difference between elements in each triad is more than, $\varepsilon_{1}\left(\varepsilon_{1} \geq \varepsilon\right)$, i.e. one should pick out a set of triads from $X^{(1, N)}$ that comply with both inequality (1) for all $q=\overline{0,2}$ and the following inequality:

$$
\left|X_{j_{k}+q}-X_{j_{k}+l}\right|>\varepsilon, \text { for all } q, l=\overline{0,2}, q \neq l, k=1,2, \ldots
$$

By expanding these triads rightwards and leftwards by way of adding elements from the sequence in question according to their sequence order $X^{(1, N)}$ we can form the chains $X^{\left(i_{k}, m_{k}\right)}(k=\overline{1, n})$ belonging to the $\varepsilon$-tubes (complying with inequality (1)) in which each separate element from $X^{(1, N)}$ with its fixed number can be found in $X^{(1, N)}$ not more than once.

Now from the sets of such chains belonging to $\varepsilon$ tubes, the sets of $\varepsilon$-chains are extracted that have maximum length while keeping maximum concentration of elements in them at every step of their expansion.

Then, for the $\varepsilon$-chain sets obtained, for each $q=\underline{m}, \bar{m}$, the average $\overline{X_{q}}$ are calculated and used as words (or patterns or matrices).

\section{Example of Identifying Patterns in the Heart Rate}

The procedure described above was applied to extract patterns (matrix sequences) from the sequences of RRintervals measured accurate to $0.01 \mathrm{sec}$ that comprised 6070 elements all together taken from seven different surveyed persons.

Table 1 shows an example of extraction of the repeating fragments and their corresponding matrix sequence from a 750-RR-interval sequence taken from surveyed person A's ECG.

A large share of elements of the matrix sequences can be observed within their initial RR-interval sequences (up to $60 \%$ and over $23 \%$ on average). Especially frequent are the roots - they are repeated in the samples in question with $\varepsilon$-accuracy in dozens. It suggests a great share of determinacy in the ECG RRinterval sequences. In this respect, a slight influence (within $\varepsilon$ ) of 'random' factors can take place at every step, while their significant influence is also possible but not indispensable at forming every ECG RR- 
interval. Thus, the heart rate is sort of set up in advance, for several following steps.

Table 1. Surveyed person A's RR-interval fragments corresponding to an individual matrix sequence

\begin{tabular}{|c|c|c|c|c|c|c|}
\hline \multirow{2}{*}{$\begin{array}{c}\text { Numbers of repeating } \\
\text { sequence elements }\end{array}$} & \multicolumn{7}{|c|}{ Repeating RR-interval sequences, } \\
\cline { 2 - 8 } & 1 & 2 & 3 & 4 & 5 & 6 \\
\hline $89-93$ & 0.67 & 0.70 & 0.98 & 0.89 & 0.70 & - \\
\hline $221-225$ & 0.67 & 0.70 & 0.97 & 0.88 & - & - \\
\hline $250-254$ & 0.68 & 0.69 & 0.98 & 0.88 & 0.71 & 0.71 \\
\hline $284-289$ & 0.70 & 0.70 & 0.98 & 0.89 & 0.70 & 0.72 \\
\hline $336-369$ & - & 0.70 & 0.99 & 0.89 & 0.68 & - \\
\hline Matrix sequence & $\mathbf{0 . 6 8}$ & $\mathbf{0 . 7 0}$ & $\mathbf{0 . 9 8}$ & $\mathbf{0 . 8 9}$ & $\mathbf{0 . 7 0}$ & $\mathbf{0 . 7 2}$ \\
\hline
\end{tabular}

\section{Fifteen Types of Poincaré Plots of Heart Rate}

It is of interest to draw confirmation of the results achieved through a simpler method. For this purpose, 342 sequences taken from 309 persons at rest at different times of day and year were processed, each of the sequences comprising 2000 ECG RR-intervals. For each such sequence, the points $\left(X_{1}, X_{2}\right),\left(X_{2}, X_{3}\right), \ldots$, $\left(X_{N-1}, X_{N}\right)$ were consecutively marked on the plane with coordinates $(x, y)$, thus creating distributions of $N$ $(N=1999)$ complementary intervals which are nowadays called Poincaré plot heart rate variability (HRV).

Individual areas that possess various positions, configurations, and tightnesses are identified within these distributions presented in Fig. 1. To the right of each such distribution, one can find the margins of the area of its registration along the $X$ and $Y$ axes in seconds.

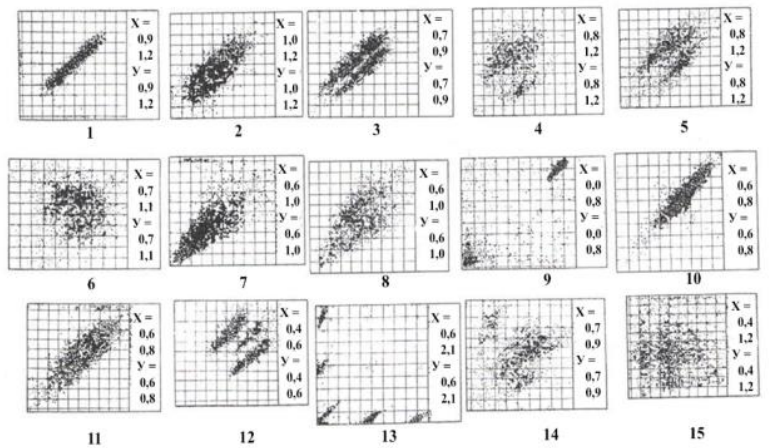

Fig. 1. 15 types of Poincaré plots HRV presented by Cherkay A.D. and Vlasov Yu.A. in their paper [1].

As the Poincaré plots are being built, the $i$-th RRinterval is put on the horizontal $X$ axis, and the next, $(i+1)$-th RR-interval $(i=1,2, \ldots, 1999)$ is put on the vertical $Y$ axis.

In [1], the obtained 342 point distributions in Poincaré plot were divided by the frequencies, positions, and appearance of their areas into 15 types recurrently observed in a particular person or various persons. The appearance of these areas shows that pairs, triads, or even longer RR-interval sequences do repeat. Repeatability of pairs and triads of RR-intervals is especially clearly manifested in the Poincare chart of the 13th type found in 29 patients. For this type of Fig. 1, the triads and quadruples of the RR intervals are repeated up to a hundred times at $\varepsilon=0.06 \mathrm{sec}$.

\section{Analysis of Shapes in Heart Rate Poincaré Plots}

In [27], the results of checking the repeatability of 15 types of Poincaré plots revealed in [1] using the night data (at rest) of the 24 hour records of RRintervals of 216 patients from the database Physionet were presented in [28]. The repeatability of most types of Poincaré plots was confirmed, and two types of these diagrams were identified, which could be new. Their additional analysis showed that they may be and variants of the 13th type, but in the range of $R R$ intervals from $0.6 \mathrm{sec}$ to $1.5 \mathrm{sec}$. With an additional cloud on the diagonal in the range of RR intervals from 0.4 seconds to 0.6 seconds in one of these two types.

Their further analysis in the Poincaré plots let the authors discover geometric shapes that in some instances looked like letters and other symbols used in written language, as well as parts of circles or ellipses. A specific feature of those shapes is that most of them appear in a Poincaré plots as empty (free of dots) spaces (see types 4, 6, 14, 15 in Fig. 1 with $3 x$ zooming, and zoomed-in diagram for type 15 in Fig. 2 rotating them 90 degrees clockwise and counterclockwise). Naturally, such a phenomenon requires additional testing which is just being carried out by the authors. But whatever the outcome will be, the phenomenon is of great interest because it reveals possible two-tier nature of the information contained in the signals of living systems. One of those tiers probably shows the presence of various RR-interval combinations in the recorded processes, while the other one relates to the absence of such combinations.

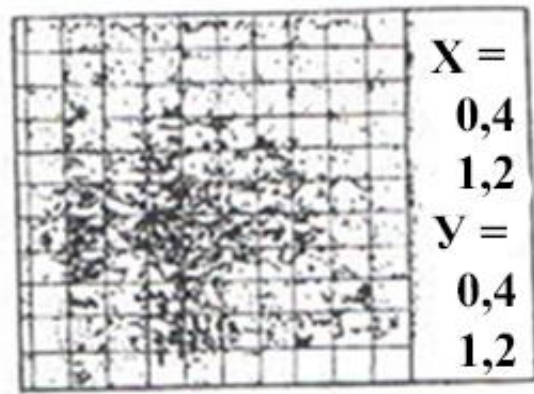

Fig. 2. Type 15 diagram with $3 \mathrm{x}$ zooming for Poincaré plot HRV taken from Fig. 1.

Let us note finally that the linguistic approach, based on the analysis of fragments of dynamic data series, can be used to solve problems of description, forecasting and management in a wide range of fields, and not only in biology. An example of such an application in the economy is given in [29]. 


\section{References}

1. Cherkay A.D., Vlasov Yu.A. Linguistic Analysis of the Human Heart Rate. In: The Issues of Temporal Organization of Living Systems: Collected Works of the Department of Physiology of Academy of Sciences of the USSR. Moscow: Nauka Publishers, 1979. P. 62-70 (in Russ.).

2. Vlasov Yu.A., Yashkov V.G., Yakimenko A.V., Cherkay A.D., Melnikova N.N. The method of sequential pair analysis of the rhythm of the heart in the intervals $R-R$. Novosibirsk: Radioelectronics, physics and mathematics in biology and medicine, 1971. P. 9-14 (in Russ.).

3. Meshalkin Ye.N., Vlasov Yu.A., Cherkay A.D., Glushkov N.N., Melnikova N.N. One approach to identification of random and regular elements in the heart rate management strategy. Krovoobrashcheniye (Yerevan). 1973. V. 6. № 5. P. 12-16 (in Russ.).

4. Goldstein P.A., Barnett G.O. A statistical study of the ventricular irregularity of atrial fibrillation. Comput. and Biomed. Res. 1967. V. 1. № 2. P. 147-161.

5. Haisty W.K., Batchlot C., Cornfield J., Pipberger H.V. Discriminant function analysis of RRinterval: an algoritm for on-line arrhythmia diagnosis. Comput. and Biomed. Res. 1972. V. 5. № 3. P. 247-255.

6. Parin V.V., Baevsky P.M. Introduction to medical cybernetics. Moscow: Medicine, 1967. 220 p. (in Russ.).

7. Baevsky R.M. Forecasting states on the verge of norms and pathologies. Moscow: Medicine, 1979. 295 p. (in Russ.).

8. Bayevsky P.M., Kirillov O.I., Kletskin S.Z. Mathematical analysis of heart rate changes under stress. Moscow: Science, 1984. 220 p. (in Russ.).

9. Baevsky R.M., Ivanov G.G., Chireikin L.V., Gavrilushkin A.P., Dovgalevsky P.Ya., Kukushkin Yu.A., Mironova T.F., Prilutsky D.A., Semenov A., Fedorov V.F., Fleishman A.N., Medvedev M.M. Analysis of heart rate variability when using various electrocardiographic systems. Herald of arrhythmology (St. Petersburg). 2002. № 24. P. 65-86 (in Russ.).

10. Sassi R., Cerutti S., Lombardi F., Malik M., Huikuri H.V., Peng C.K., Schmidt G., Yamamoto Y. Advances in heart rate variability signal analysis. Europace. 2015. V. 17. № 9. P. 1341-1353. doi: 10.1093/europace/euv015.

11. Kamen P.W., Krum H., Tonkin A.M. Poincare plot of heart rate variability allows quantitative display of parasympathetic nervous activity in humans. Clinical Science. 1996. V. 91. № 2. P. 201-208. doi:10.1042/cs0910201.

12. Brennan M., Palaniswami M., Kamen P. Do existing measures of Poincare plot geometry reflect nonlinear features of heart rate variability? IEEE transactions on biomedical engineering.
2001. V. 48. № 11. P. 1342-1347. doi: $\underline{10.1109 / 10.959330}$

13. Piskorski J., Guzik P. Geometry of the Poincar'e plot of RR intervals and its asymmetry in healthy adults. Physiol. Meas. 2007. V. 28. P. 287-300. doi: 10.1088/0967-3334/28/3/005.

14. Khandoker A.H., Karmakar C., Brennan M., Palaniswami M., Voss A. Poincaré Plot Methods for Heart Rate Variability Analysis. Springer London, 2013. P. 146. doi: 10.1007/978-1-46147375-6.

15. Xoshi R.A., Pastre C.M., Vanderlei L.C.M., Godoy M.F. Poincaré plot indexes of heart rate variability: Relationships with other nonlinear variables. Autonomic Neurosciece Basic \& Clinical. 2013. V. 177. № 2. P. 271-274. doi: 10.1016/j.autneu.2013.05.004.

16. Kulinkovich A.Ye. Basic principles of machine processing of cardboard curves. In: Automated Processing and Conversion of Geophysical Data. Moscow: Nedra, 1965. P. 113-159 (in Russ.).

17. Pavlidis T. Linquistic analysis of waveforms. Software Eng. 1971. V. 2. № 4. P. 203-225.

18. Muchnik I.B., Muchnik R.B. Formation algorithms of the curve description language. Avtomatika i telemekhanika (Moscow). 1973. V. 5. P. 86-98 (in Russ.).

19. Yang A., Hseu S.S., Yien H.W., Goldberger A. L., PengC.K. Linguistic Analysis of the Human Heartbeat Using Frequency and Rank Order Statistics. Physical Review Letters. 2003. V. 90. № $10 . \quad$ P. 108103 . doi: 10.1103/PhysRevLett.90.108103.

20. Gurov Yu.V., Zaguskin S.L. Chronodiagnostic Capabilities of the Symbolic Dynamics Method. Terapevticheskiy arkhiv (Moscow). 2011. V. 83. № 4. P. 23-26.

21. Uspensky V.M. Information function of the heart. Theory and practice of diagnosis of diseases of internal organs by the method of information analysis of electrocardiosignals. Moscow: Economics and Informatics, 2008. 151 p. (in Russ.).

22. Uspensky V.M., Vorontsov V.M., Zelykh V.R. Statistical check of information analysis technology of electrocardiosignals for diagnosis. In: "Mathematical Biology and Bioinformatics": presentation of the report at the conference Pushchino, 2014. URL: http://www.machinelearni ng.ru/wiki/images/9/9a/Voron-2014-10-20-ecg.pdf (accessed 28.06.2018) (in Russ.).

23. Hawkins J., Blakeslee S. On intelligence. New York: Times Books, 2004. 239 p.

24. Bodyakin V.I. Automatic construction of semantic models of arbitrary subject domains on base of neuron semantic approach. In: Open Semantic Technologies for Intelligent Systems: materials of the II International Scientific and Technical Conference. Minsk: BSUIR, 2012. P. 8-90 (in Russ.) 
25. Eckmann J.P., Kamphorst S.O., Ruelle D. Recurrence Plots of Dynamical Systems. Europhysics Letters. 1987. V. 5. № 9. P. 973-977. URL: http://www.ihes.fr/ ruelle/PUBLICATION S/\%5B92\%5D.pdf (accessed 28.06.2018).

26. Marwan N., Romano M.C., Thiel M., Kurths J. Recurrence Plots for the Analysis of Complex Systems. Physics Reports. 2007. V. 438. № 5-6. P. 237-329.

URL: http://citeseerx.ist.psu.edu/viewdoc/downloa $\underline{\mathrm{d} \text { ?doi }=10.1 .1 .93 .2883 \& \mathrm{rep}=\mathrm{rep} 1 \& \mathrm{type}=\mathrm{pdf}}$ (accessed 28.06.2018).

27. Cherkay A.D., Vlasov Yu.A. Language of Heart Rate. In: Neuroinformatics-2016: collection of research papers of the XVIII International Academic Conference in 3 volumes. Moscow: NIYAU MEPHI, 2016. V. 3. P. 142-151 (in Russ.).

28. Database Physionet. URL: https://www.physionet. org/physiobank/database/ (accessed 28.06.2018).

29. Cherkay A.D. Linguistic models in macroeconomics, microeconomics and accounting. In: Annual Scientific Conference Lomonosov Readings-2018. Section of Economic Sciences "Digital Economy: Man, Technology, Institutions": The collection of theses. Moscow: Moscow State University, 2018. P. 534-537. URL: https://www.econ.msu.ru/sys/raw.php?o=47 884\&p=attachment $\quad$ (accessed 28.06.2018) (in Russ.). 